\title{
Gestão de relacionamento com líderes: desafio para o ouvidor
}

Management of relationship with leaders:

a challenge for the listener

La gestión de la relación con los líderes:

un desafío para el defensor

\section{Chussely Souza Lima}

- Mestre em Gestão Pública pela Universidade Federal de Pernambuco (UFPE)

- Especialista em Administração de Marketing, Gestão da Qualidade em Serviços e Planejamento e Gestão Organizacional, pela Universidade de Pernambuco (UPE)

- Graduada em Relações Públicas pela Universidade Católica de Pernambuco (Unicap)

- Professora titular, vice-coordenadora do Curso de Relações Públicas e professora da pós-graduação no curso de Gestão de Ouvidoria da Escola Superior de Relações Públicas (Esurp)

- Professora do Curso de Gestão de Ouvidoria da UPE, na formação dos ouvidores do Governo do Estado

- chussely@yahoo.com.br 
Resumo

Este trabalho procura refletir sobre a importância e a gestão dos relacionamentos por meio da comunicação dirigida para os resultados da ouvidora, dando ênfase àquele público constituído pelos líderes das áreas, responsáveis por responder as manifestações. Conclui-se que ainda não há evidência sobre o profissional ideal para a função de ouvidor, mas que o mercado de ouvidoria depende de habilidades comunicacionais.

PALAVRAS-CHAVE: OUVIDORIA • GESTÃO DE RELACIONAMENTO • COMUNICAÇÃO DIRIGIDA

\section{Abstract}

This work is a reflection on the importance and management of relationships, through communication focused on the listener's results, stressing the public that consists of leaders of the areas responsible for responding to the complaints. One concludes that there is no evidence concerning the ideal professional ideal to play the role of listener, but that the listening market relies on communication skills.

KEYWORDS: LISTENER • RELATIONSHIP MANAGEMENT • DIRECTED COMMUNICATION

Resumen

Este trabajo busca reflexionar sobre la importancia y la gestión de las relaciones a través de la comunicación dirigida a los resultados de la defensoría. Se enfatiza el público constituido por los líderes de las áreas, responsables de responder a las manifestaciones. Se concluye que todavía no hay evidencias sobre el profesional ideal para la función de defensor, pero que el mercado de defensoría depende de habilidades comunicativas.

PALABRAS CLAVE: DEFENSORÍA • GESTIÓN DE RELACIONES • COMUNICACIÓN DIRIGIDA 
0 mundo contemporâneo impõe a cada dia a necessidade de cultivar e aprimorar relacionamentos a fim de obter resultados efetivos, tanto na vida pessoal como na profissional, sendo preciso para tanto incrementar as habilidades comunicacionais. Parcerias, fusões, modelos de gestão participativa, participação nos lucros são estratégias modernas de relações aproximativas em prol de compartilhamento de resultados.

Essa necessidade de cultivar novos relacionamentos não é diferente nas ouvidorias. Uma instituição que cataloga uma variedade de públicos, como a ouvidoria, necessita conhecê-los e utilizar a comunicação para fazer a gestão dos seus relacionamentos de forma a fomentar esses resultados também para a organização da qual faz parte. "O sistema comunicacional é fundamental para o processamento das funções administrativas internas e do relacionamento das organizações com o meio externo" (KUNSCH, 2003, p. 69).

A redemocratização do Brasil trouxe um grande impulso para as atividades de defesa do consumidor e as ouvidorias em todo o País. Desde a criação da primeira ouvidoria pública brasileira, em 1986, na cidade de Curitiba (PR), até hoje, muitas ouvidorias foram criadas Atualmente apenas em Brasília há cerca de 260 ouvidorias ligadas ao governo (federal e distrital) ${ }^{1}$. Apesar de estar em curso uma pesquisa mais abrangente ${ }^{2}$, não existem informações consolidadas sobre o número de ouvidorias no Brasil.

Fazer a gestão dessas ouvidorias é um desafio para os ouvidores, quando muitas delas, no Brasil, ainda são confundidas com centrais de atendimento ao cliente e ainda não conseguiram formar uma identidade como a última instância do cliente em relação à organização.

Assumir a responsabilidade de gerir uma ouvidoria é desafio dos maiores em tempos de sociedades conscientes do seu poder de participação com críticas, sugestões, reclamações, denúncias na formação, consolidação e melhoria das organizações (LIMA, 2008, p. 34).

De acordo com o perfil da organização - produtos ou serviços, segmento, decisão da gestão, capacidade de atendimento -, as ouvidorias têm diferentes públicos. Algumas atendem exclusivamente o público externo: clientes, consumidores e cidadãos; outras atendem também seu público interno: funcionários, servidores e colaboradores, entre outras formações. Essas diferenças não serão particularizadas neste trabalho, assim como não se fará a distinção entre ouvidoria pública ou privada.

1 Informação cedida pelo Instituto Nacional de Capacitação (INC) (INC, 2009).

2 Manoel Eduardo Camargo e Gomes, doutor em Direito, primeiro ouvidor público do Brasil e professor da Universidade Federal do Paraná (UFPR), está desenvolvendo uma pesquisa sobre as ouvidorias públicas do Brasil, por meio do Núcleo de Pesquisa de Controle do Estado, com apoio do Conselho Nacional de Desenvolvimento Científico e Tecnológico (CNPq). A pesquisa tem conclusão prevista para junho de 2010 . 
Observando as ouvidorias como uma instituição, é possível identificar quatro grupos de públicos mais específicos com os quais ela se relaciona e que foram utilizados na pesquisa para este trabalho. O primeiro grupo é composto por clientes, consumidores e cidadãos; o segundo, pela gestão da organização (presidente, secretário de Estado, gestor maior); o terceiro, pelos responsáveis por responder às demandas/manifestações (gestores de áreas, líderes); e o quarto, por funcionários e servidores em geral.

\section{A PESQUISA}

Este ensaio tem por objetivo obter respostas para alguns questionamentos sobre a importância e a gestão dos relacionamentos por meio da comunicação dirigida para os resultados da ouvidora. Em uma primeira abordagem, refletiremos sobre os relacionamentos da ouvidoria, seguida por uma pontuação acerca da comunicação dirigida na gestão desses relacionamentos. Para isso, faremos uma breve ponderação sobre a importância do planejamento e do gerenciamento da comunicação como meio para conquistar a efetividade da ouvidoria. Vale ressaltar uma evidente fragilidade teórica no que tange à transversalidade das temáticas ouvidoria, gestão e comunicação, o que justifica, sobremaneira, este trabalho.

Inicialmente a pesquisa foi planejada para retratar o perfil das ouvidorias públicas, privadas e do terceiro setor de Pernambuco no tocante aos relacionamentos com seus públicos. No entanto, a amostra direcionou o trabalho para as ouvidorias públicas. Durante o segundo semestre de 2009, realizamos o levantamento bibliográfico e a pesquisa de campo com os ouvidores, objetivando identificar a importância da gestão de relacionamento para a efetividade da ouvidoria. Buscamos conhecer o impacto que o desenvolvimento de estratégias de relacionamento, por meio da comunicação dirigida, especialmente aos líderes das organizações, pode gerar na qualidade das respostas por eles dadas aos clientes. Ter conhecimento da percepção dos ouvidores sobre esses pontos permite avaliar a importância que a comunicação tem para as ouvidorias públicas de Pernambuco, assim como a relação das estratégias aproximativas com a qualidade das respostas que chegam às mãos dos clientes.

Os dados coletados serão expostos na tentativa de encontrar, entre a teoria e a prática, as respostas para as premissas que subsidiaram a pesquisa. Qual o público para o qual a ouvidoria desenvolve mais ações de relacionamento? A qualidade das respostas às manifestações está vinculada ao relacionamento estabelecido com o público que a produz? As ouvidorias que são geridas por profissionais de relações públicas desenvolvem mais ações de relacionamentos? Se sim, os seus resultados são mais efetivos?

E, para avaliar especificamente a efetividade da ouvidoria, foi pesquisada a qualidade das respostas das demandas a fim de fazer uma análise maior 
entre as premissas acima relacionadas e o produto do trabalho do público escolhido como foco da pesquisa: os líderes e gestores de áreas responsáveis por responder as manifestações. Para mensurar a qualidade das respostas das manifestações, foram estabelecidas quatro variáveis: prazo de entrega, clareza, conteúdo e pertinência.

Qual a importância de cada público com que a ouvidoria se relaciona? Qual a força de trabalho dedicada a cada um desses públicos? São desenvolvidas ações de relacionamento com comunicação dirigida destinadas a esses públicos como eventos, reuniões, divulgações, visitas etc.? A formulação das questões buscou verificar mais de perto informações que levassem a confirmação das hipóteses conferindo com a fundamentação teórica delimitada para o trabalho.

A primeira etapa da pesquisa consistiu na definição do universo das ouvidorias, com informações obtidas por meio seccional de Pernambuco da Associação Brasileira de Ouvidores (ABO), da Rede de Ouvidores Públicos do Estado de Pernambuco e do banco de dados da pesquisadora ${ }^{3}$. A constituição da amostra resultante da primeira etapa da pesquisa acabou por direcionar o trabalho para o universo das ouvidorias públicas do Estado de Pernambuco. A amostra, nãoprobabilística, por tipicidade 4 , foi representada por 33 ouvidorias, sendo 29 públicas, 01 do terceiro setor e 03 de economia mista. Das ouvidorias públicas, 01 era da esfera municipal e 28 integravam a esfera estadual. Nas ouvidorias estaduais vale destacar a diversidade de segmentos que constituem o grupo: tribunais, hospitais, secretarias de Estado, agências reguladoras e instituições de ensino como universidades e a Escola Politécnica. Essa variedade proporcionou um caráter heterogêneo à pesquisa.

Para a segunda etapa da pesquisa tomou-se como base a classificação de Vergara (2006). Asssim, quanto aos fins, a pesquisa foi exploratória, em virtude da ausência de ensaio similar analisando o relacionamento com o público específico de ouvidorias no Estado, e descritiva, visto que expôs características das ouvidorias selecionadas para o estudo e também por estabelecer correlações entre as variáveis pesquisadas. Quanto aos meios, foi bibliográfica e de campo. A fundamentação teórica possibilitou uma investigação bibliográfica sobre relacionamento, comunicação dirigida e planejamento de comunicação com foco na efetividade dos seus resultados.

A aplicação da pesquisa de campo, que constituiu a terceira etapa, ocorreu durante um mês, por meio da aplicação de questionários com perguntas abertas e fechadas, com orientação e esclarecimento da pesquisadora em evento

3 A ouvidoria pública do Estado de Pernambuco é tema de estudo da autora desde 0 ano 2000. Mais informações em Lima (2008).

4 "Constituída pela seleção de elementos que o pesquisador considere representativos da população-alvo" (VERGARA, 2006, p. 51) 
da qual participou ${ }^{5}$, e por meio da rede internacional de computadores, via correio eletrônico (VERGARA, 2006).

A avaliação dos questionários, a codificação das respostas e a tabulação dos dados permitiram também delinear a escolaridade, identificando a formação superior dos ouvidores, idade da ouvidoria, o sexo do ouvidor e o volume médio mensal de demandas, o que subsidiou de forma proeminente a análise dos dados.

\section{OUVIDORIA, CAMPO DE RELACIONAMENTO}

Este trabalho tem como objetivo refletir sobre a importância de fazer a gestão dos relacionamentos dos públicos da ouvidoria, como forma de conquistar resultados efetivos para esta e, consequentemente, para a organização, dando ênfase àquele público constituído pelos líderes e gestores de áreas responsáveis por responder as manifestações. Trata-se de um público relevante na gestão da ouvidoria, pelo fato de ser formado por profissionais que têm em suas mãos tanto o questionamento do demandante como o conhecimento da área questionada e serem, portanto, um importante canal condutor de informações.

É um público que necessita muito da atenção do ouvidor, em virtude de a forma como a demanda é trabalhada por ele refletir diretamente na qualidade da resposta que o cliente receberá e no subsídio que a gestão estratégica da organização terá para a tomada de decisão quanto aos assuntos que entram em questão.

O estabelecimento de relacionamentos sólidos com seus diversos públicos de interesse, sejam eles internos ou externos à organização, pode constituir um grande diferencial em momentos [em] que a informação que tramita nessa organização seja uma ferramenta relevante em acompanhamento a uma demanda (LIMA, 2008, p. 35).

Valéria de Siqueira C. Lopes (2002, p. 93), em estudo sobre cultura e comunicação na relação entre empresas e consumidores, diz que "é pela importação e transformação de dados obtidos dos consumidores que a organização consegue adaptar produtos ou serviços em busca de melhorias, caracterizando a mudança e o desenvolvimento organizacionais". Nesse sentido, o desenvolvimento e a manutenção de um bom relacionamento entre a ouvidoria e os líderes responsáveis por responder às demandas são fundamentais na informação e transformação dos dados obtidos com as manifestações. A autora ainda se refere à tipologia da cultura organizacional abordada por Robert Ernest (1985, p. 49-60), que remete aos relacionamentos e à comunicação entre públicos de uma organização:

5 Seminário "A ouvidoria pública: instrumento de controle e participação social", realizado no dia 28/10/2009 em Recife (PE), em comemoração ao primeiro ano de oficialização da Ouvidoria-Geral do Estado de Pernambuco. 
As empresas são classificadas como participativas, ou seja, com forte comunicação e suscetíveis às necessidades e aos interesses de funcionários e consumidores; ou não-participativas, isto é, inábeis nas relações com empregados e consumidores. [...] As empresas classificadas como participativas são suscetíveis às necessidades dos consumidores e possuem forte comunicação, indicando a tendência à manutenção das boas relações com o público e a preocupação em atendê-lo.

A ouvidoria, como locus de participação, necessita cultivar boas relações como forma de conhecer particularmente seus públicos e assim criar proximidade e intimidade. Estreitar os vínculos é uma forma imprescindível de conhecer as peculiaridades do outro e assim compreender suas necessidades e suas reações. Reconhecer o seu público denota a possibilidade de compreender as motivações envolvidas no desenvolvimento e na execução das suas atividades. Sendo assim, fica possível a criação de novos ritos que permitem o surgimento de compromissos mútuos.

Essa afinidade sustenta o relacionamento e conduz a um ciclo que transforma o trabalho realizado em conjunto em parceira positiva. Acaba-se por reconhecer o público e suas necessidades, tanto em momentos de estabilidade organizacional como nas crises. É possível então transpor desafios comuns, pois à ouvidora cabe apenas o papel de mediação e não de interferência na gestão. O desafio torna-se comum, no sentido de que todos buscam a solução para a manifestação, entretanto, cada um no seu papel: a ouvidoria mediando e o gestor interferindo, modificando ou melhorando processos. Assim é possível estabelecer relacionamentos sólidos e duradouros.

Gerson Bonfadini (2006), em estudo sobre relacionamento organizacional, aborda a sugestão de Grunig e Hon (1999), de desenvolvimento de um instrumento de avaliação do relacionamento organizacional no longo prazo por meio de uma escala de mensuração composta por seis atributos, a saber: controle mútuo - as partes concordam com a legitimidade do poder de influenciar um ao outro; a confiança, que representa a confiabilidade apresentada em três dimensões - integridade, coerência e competência; a satisfação, que é reforçada pelas expectativas positivas; o comprometimento, que demonstra a crença em manter o relacionamento; o relacionamento de troca, que beneficia as partes; e, finalmente, o relacionamento em comum, no qual existe o interesse no bem-estar da outra parte, mesmo sem obter retorno (GRUNIG e HON, 1999, apud BONFADINI, 2006).

Essa abordagem traz à tona a reflexão de que, para conquistar relacionamentos duradouros, é preciso despertar a intenção das partes envolvidas. Nesse sentido, a comunicação passa a ser uma grande aliada para o desenvolvimento dos atributos sugeridos que, acreditamos, além da durabilidade dos relacionamentos, contribuem para a sua qualidade e, consequentemente, influenciam na construção da imagem da ouvidoria. "O gerenciamento correto do proces- 
so de relacionamento da organização com os seus públicos possibilita a construção de uma imagem positiva e de uma opinião favorável sobre a mesma” (BONFADINI, 2006, p. 4).

Evidenciar a importância da construção de vínculos sólidos entre a ouvidoria e os diversos públicos, em especial os líderes da organização, é valorizar a capacidade da aprendizagem embutida na natureza gregária do ser vivo, abordada por Ciro Marcondes Filho (2009). O autor recorre à etologia ${ }^{6}$ para tratar dos vínculos:

O vínculo passa a ser o resultado de ações (inatas ou aprendidas) do ser vivo que o aproximam do outro ou reforçam e alimentam uma proximidade já existente. Assim, a natureza gregária das espécies sociais possui aptidões inatas para a geração dos primeiros vínculos e uma capacidade de aprendizagem para os vínculos mais complexos da vida social (MARCONDES FILHO, 2009, p. 354).

No ambiente de ouvidoria, muitos são os desafios na busca de resultados efetivos e a criação e a manutenção de vínculos tem implicação direta com esses resultados. É preciso aprender a cultivar os vínculos com seus públicos de interesse, sendo assim basal conhecer o outro. Estreitar laços começa com a iniciativa da comunicação, do tornar-comum, que, segundo o mesmo autor, tem a ver com a relação com o outro e com as coisas, "portanto uma forma de relação que desenvolvo com o mundo circundante" (MARCONDES FILHO, 2008, p. 19). É como voltar à origem, firmar o conceito da comunicação como sustentação dos relacionamentos, que é antes de tudo condição básica para a vida social e, consequentemente, econômica e política. Afinal, “a empresa é uma síntese, um ‘condensado’ do mundo que há lá fora, com mecanismos semelhantes e sistemas de poder e colaboração equivalentes" (MARCONDES FILHO, 2008, p. 161).

\section{COMUNICAÇÃO DIRIGIDA:}

\section{ESTRATÉGICA PARA A OUVIDORIA}

Criar aproximação entre a ouvidoria e seus públicos não é por certo uma tarefa simples, visto que posicionamentos contraditórios sobre as demandas são frequentes, principalmente entre o ouvidor, como representante do cliente e cidadão, e os líderes responsáveis por responder às manifestações. Ainda é lugar-comum a percepção distorcida de gestores em enxergar a ouvidoria como o "dedoduro" ou aquela área que vai expor os defeitos da sua área. Isso gera, muitas vezes, um clima de instabilidade e conflitos.

6 Etologia "é uma das áreas que se ocupa da questão do vínculo" (MARCONDES FILHO, 2009, p. 354). 
A comunicação é o instrumento ideal para mediar relacionamentos e construir a integração entre públicos divergentes, indo além da capacidade de informar, considerando-se o seu sentido mais amplo de tornar algo comum às partes que se relacionam. "Comunicação é um ato de comunhão de ideias e o estabelecimento de um diálogo. Não é simplesmente uma transmissão de informações” (KUNSCH, 2003, p. 161) Ao escolher um público específico com o qual se tem o propósito de desenvolver uma comunicação interativa, torna-se necessária a utilização da comunicação dirigida, que, segundo Antonio Vasconcelos e Celso Oliveira (apud KUNSCH, 2003, p. 186-187), é

uma forma de comunicação humana destinada a propiciar maior interação entre pessoas e grupos, pois, quanto mais direta for, melhor será o resultado de qualquer comunicação. Na comunicação dirigida comunicador e receptor se identificam.

No mundo globalizado, as empresas já percebem a importância da comunicação na relação entre as boas práticas de gestão e governança e a necessidade de equilíbrio no relacionamento com seus públicos. Em depoimento à revista Comunicação Corporativa, o diretor de comunicação e marca da Atento, empresa especializada em serviço de atendimento, Luís Alcubierre (apud CASTRO, 2008, p. 50), reforça a importância da comunicação dirigida e destaca que "o sucesso de uma empresa depende da capacidade que as pessoas têm de se comunicar e ser relacionar internamente".

A comunicação dirigida pode ser aplicada de quatro maneiras: escrita, oral, auxiliar e aproximativa. A escrita apresenta-se de várias formas, tais como: correspondências, mala-direta e publicações. A oral se dá por meio de discursos, reuniões, conversas face a face e eventos como conferências, painéis, mesasredondas, fóruns, assembleias, entre outros. A comunicação dirigida auxiliar, além de todos os meios digitais e telemáticos, comuns aos dias atuais, utiliza recursos audiovisuais como vídeos, filmes, vídeojornal etc. E a aproximativa, que é interativa e presencial, refere-se a visitas às instalações da organização, eventos, comemorações etc., ou seja,ações que provoquem o contato direto com os públicos (ANDRADE, 1993, apud KUNSCH, 2003, p. 187),

Entretanto, é indispensável o planejamento para que os resultados da comunicação dirigida alcancem seus objetivos na gestão dos relacionamentos de uma ouvidoria. "É imprescindível planejar o processo de inter-relacionamento das organizações com seus públicos, adotando estratégias e técnicas apropriadas e utilizando instrumentos adequados para cada segmento de público que se quer atingir" (KUNSCH, 2003, p. 103). É preciso enxergar essa ação como parte de um planejamento maior, pois toda comunicação desenvolvida deve estar integrada ao planejamento estratégico da organização como um todo, a fim de alinhar as ações e maximizar os resultados de forma coerente. 
O novo ouvidor precisa ter consciência de que o propósito final de toda organização, independentemente de sua característica - empresa privada, pública ou do terceiro setor - é produzir ou ofertar bens ou serviços de qualidade, com eficiência na obtenção de lucros e satisfação do seu cliente. Visto dessa forma, clientes e organizações possuem os mesmos interesses quando se trata da prestação do serviço, e, portanto, ao ouvidor não é diferente (LIMA, 2008, p. 34).

Planejar as ações de comunicação de uma ouvidoria não se restringe a colocar em prática ações estabelecidas em um documento dentro dos prazos e dos custos previstos. O planejamento impede que as organizações coloquem suas atividades em prática de forma casual, devendo elas ficar atentas aos princípios fundamentais do planejamento, ou seja, a eficiência, a eficácia e a efetividade, esclarecidos desta forma por Kunsch (2003, p. 305);

Eficiência significa fazer bem-feito, de maneira adequada, com redução de custos, desempenho competente e rendimento técnico. Eficácia liga-se a resultados - em função dos quais é preciso escolher alternativas e ações corretas, usando tanto conhecimento e criatividade para fazer o que é mais viável e certo. Efetividade relaciona-se com a permanência no ambiente e a perenidade no tempo, no contexto da obtenção dos objetivos globais.

Para conquistar a efetividade das ações da ouvidoria, é preciso desenvolver competências de gestão, a fim de transpor o papel de executor, visualizando suas atitudes como subsídios para a consolidação da credibilidade da ouvidoria. As ações necessitam de sustentabilidade, para o que é fundamental que estejam alinhadas com os objetivos da gestão, sua execução seja viável e bem realizada, atentando para os custos e a competência técnica envolvidas na implantação, e que seus resultados sejam permanentes.

\section{GESTÃO DE RELACIONAMENTO: EM BUSCA DE RESULTADOS EFETIVOS}

A pesquisa que aplicamos em ouvidorias públicas, privadas, de empresas mistas e organizações não-governamentais (ONGs) possibilitou uma análise da formação superior dos ouvidores, demonstrando que se igualavam com $18 \%$ as ouvidorias lideradas por administradores, advogados e assistentes sociais. Profissionais de relações-públicas e contabilistas estavam à frente das ouvidorias em $9 \%$ dos casos. Os psicólogos representavam apenas $6 \%$ dos ouvidores e $18 \%$ tinham diversas formações, a saber: secretariado executivo, letras, história, medicina, jornalismo e turismo, com 01 ouvidor cada. Ainda foi identificado um ouvidor sem formação superior, representando 3\% do grupo. Esses dados estão demonstrados no Gráfico 1 em números absolutos. Ainda quanto às características dos ouvidores, identificou-se a predominância de mulheres, que representavam $67 \%$ dos ouvidores, contra $33 \%$ do sexo masculino. 


\section{Gráfico 1 - Formação superior dos ouvidores}

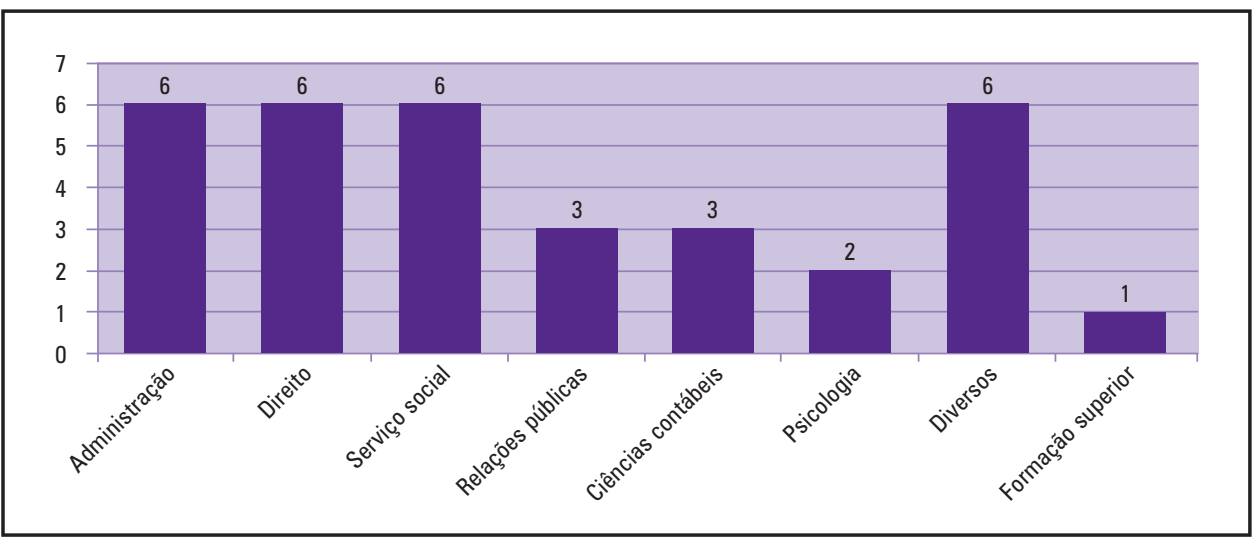

Fonte: A autora

A média de idade das ouvidorias, na época da pesquisa, era de três anos e três meses e o volume médio mensal de manifestações, 143 , valendo salientar que não foi percebida uma relação significativa entre idade e volume mensal de demanda ou tipo de organização. Foi identificado que $88 \%$ das ouvidorias possuíam média mensal de volume de recebimento de manifestações abaixo de 100 e os demais $12 \%$ representavam um volume médio mensal de recebimento acima de 350 demandas. Destaque-se o volume médio mensal de duas instituições: a Secretaria de Educação do Poder Executivo de Pernambuco, com 800 manifestações, e o Instituto de Recursos Humanos do Governo do Estado do Estado, com 700. A ouvidoria mais antiga tinha quinze anos de idade, mas a maior parte das ouvidorias (45\%) tinha até um ano de idade e $33 \%$ delas estavam entre um ano e um mês até quatro anos. Apenas $21 \%$ estavam acima dessa idade.

Em relação à importância dos públicos, 46\% consideraram os clientes como mais importantes, seguido, dos gestores estratégicos (19\%), dos líderes responsáveis por responder às demandas $(17 \%)$ e dos funcionários (16\%). Na Tabela 1 é possível ver o percentual médio da importância, da força de trabalho e das ações de relacionamento dedicados a cada público. Chega-se à conclusão de que, apesar de figurar em terceiro lugar na importância e na força de trabalho, os líderes assumem a segunda colocação, com percentual ainda maior (21\%), em relação às ações de relacionamento dedicadas a esse público.

Para $45 \%$ das ouvidorias, os líderes representam o seu público mais importante em um percentual igual ou maior a $25 \%$. Nesse grupo de pesquisados, percebe-se um aumento tanto da força de trabalho (de $18 \%$ para $25 \%$ ) quanto das ações de relacionamento (de $21 \%$ para $31 \%$ ) direcionadas aos líderes em comparação com o grande grupo. Essas ouvidorias dedicaram 32\% de suas ações 
de relacionamento aos líderes, o que traduz um aumento significativo se se considerar a média global de $21 \%$. Podemos concluir então que, quanto maior a importância dada aos líderes, maiores a força de trabalho e as ações de relacionamento atribuídas a eles.

Tabela 1 - Percentual médio (\%) destinado a cada público da ouvidoria

\begin{tabular}{|l|c|c|c|}
\hline \multicolumn{1}{|c|}{ Públicos/Atributos } & Importância & Força de Trabalho & $\begin{array}{c}\text { Ações de } \\
\text { Relacionamento }\end{array}$ \\
\hline Clientes, consumidores, cidadãos & 46 & 48 & 41 \\
\hline Gestão estratégica da organização & 19 & 17 & 18 \\
\hline Líderes responsáveis por responder as demandas & 17 & 18 & 21 \\
\hline Funcionários, servidores em geral & 16 & 18 & 19 \\
\hline
\end{tabular}

A Tabela 2, a seguir, apresenta o percentual de ações de relacionamento direcionada aos líderes de acordo com a formação do ouvidor, demonstrando também a nota média que classifica a qualidade da resposta desse grupo às manifestações, considerando-se a nota 10 como ideal.

Tabela 2 - Ações de relacionamento destinadas aos líderes e avaliação das respostas dos líderes às demandas por formação superior do ouvidor

\begin{tabular}{|l|c|c|}
\hline \multicolumn{1}{|c|}{$\begin{array}{c}\text { Formação superior } \\
\text { do ouvidor }\end{array}$} & $\begin{array}{c}\text { Ações de } \\
\text { relacionamento (\%) }\end{array}$ & $\begin{array}{c}\text { Avaliação das } \\
\text { respostas (Nota) }\end{array}$ \\
\hline Administração & 33 & 7 \\
\hline Direito & 18 & 9 \\
\hline Serviço social & 19 & 8 \\
\hline Relações públicas & 19 & 8 \\
\hline Ciências contábeis & 13 & 4 \\
\hline Psicologia & 30 & 8 \\
\hline Diversos* & 19 & 7 \\
\hline
\end{tabular}

* Secretariado executivo, letras, história, medicina, jornalismo e turismo

Fonte: A autora

Considerando-se a média geral das notas atribuídas aos líderes pela qualidade das respostas às manifestações como 7 , a tabela acima surpreende ao apresentar nota 4 atribuída por um grupo de ouvidores que dedicam $30 \%$ de ações de relacionamento a esse público. Isso quer dizer que, apesar do alto percentual 
das ações de relacionamento direcionada aos líderes, este fato não gera um impacto na qualidade das respostas das manifestações devolvidas à ouvidoria, já que esse grupo apresenta uma nota abaixo da média. Com os demais dados não é possível identificar uma relação direta entre o percentual de ações de relacionamento com as notas atribuídas à qualidade das respostas, visto que, independentemente do percentual, as notas atribuídas permanecem muito próximas à média, sem haver grande variação.

Ao fazer uma análise das notas atribuídas à qualidade das respostas das manifestações, foi encontrada, entre o grupo que atribuiu nota acima de 8 (45\% da amostra) uma representatividade de $33 \%$ de advogados liderando as ouvidorias. Nesse grupo, aparece apenas uma ouvidoria liderada por um relações-públicas. Também foi observado, nesse mesmo grupo, um percentual comum de $17 \%$ para a importância, força de trabalho e ações de relacionamentos destinadas ao grupo dos líderes que respondem às demandas. $\mathrm{O}$ grupo com notas abaixo de 7 não sinalizada predominância de nenhuma formação, entretanto apresenta percentuais maiores nos quesitos acima relacionados, de 19\%, 18\% e $21 \%$ respectivamente. Entre as variáveis estabelecidas para mensurar a qualidade das respostas das manifestações, a que obteve média menor, 7 , foi a que pontua o prazo de entrega das respostas; as demais variáveis obtiveram a mesma média 8.

\section{CONSIDERAÇÕES FINAIS}

A gestão de ouvidoria pressupõe o desenvolvimento de relacionamentos estratégicos. É preciso muito mais que conhecer a ouvidoria, seus processos. É necessário desenvolver e cultivar relacionamentos, para, assim, estabelecer vínculos produtivos em busca de resultados efetivos. A escolha de enfatizar o público composto por produzir os posicionamentos da ouvidoria para os clientes demonstra a necessidade de melhor compreendê-lo e entender qual a sua prioridade para as ouvidorias.

A pesquisa demonstrou que o cliente é a prioridade da ouvidoria em relação à importância, à força de trabalho dedicada e ao direcionamento de ações de relacionamento. Entretanto, as lideranças aparecem logo em seguida, ficando à frente do nível estratégico e do corpo funcional, em relação ao desenvolvimento de estratégias aproximativas, o que demonstra a consciência dos ouvidores em relação ao valor de estreitar relacionamentos com os líderes das organizações, os responsáveis pelas respostas que serão entregues aos clientes.

Não existe na legislação brasileira regulamentação profissional para a ocupação do cargo de ouvidor ${ }^{7}$. Entretanto, na reflexão de Kunsch (2003, p. 95) sobre

7 Projeto de Lei n. 342, de 2007, dispõe sobre a regulamentação da atividade de ouvidor, nas empresas públicas ou privadas, e dá outras providências. seu autor é o deputado Sérgio Barradas Carneiro e seu relator, o deputado Luiz Bassuma. 
a atividade profissional das relações públicas, várias pontuações corroboram aptidões fundamentais ao exercício da função de ouvidor:

As relações públicas enfatizam o lado institucional e corporativo das organizações. Em síntese, como atividade profissional, elas: identificam os públicos, suas reações, percepções e pensam em estratégias comunicacionais de relacionamentos de acordo com as demandas sociais e o ambiente organizacional; supervisionam e coordenam programas de comunicação com públicos - grupos de pessoas que se auto-organizam quando uma organização os afeta ou viceversa. preveem e gerenciam conflitos e crises [pelas quais] porventura passam as organizações e podem despontar dentro de muitas categorias: empregados, consumidores, governos, sindicatos, grupos de pressão etc.

É certo que o mercado de ouvidoria é crescente e revela oportunidade de trabalho para especialistas em relacionamento. No entanto, a pesquisa revelou que o percentual de ouvidorias lideradas por esses profissionais não é relevante e não demonstra relação direta com a efetividade da ouvidoria no tocante à qualidade das respostas às manifestações dos clientes. O reconhecimento da necessidade de desenvolver habilidades de relações públicas se dá até mesmo por parte de especialistas em ouvidoria, como Marco A. Bastos (2006, p. 19)

Para desempenhar estas e outras funções exigem-se qualificações do ombudsman ${ }^{8}$ que vão além do notável saber, de sólidos conhecimentos jurídicos, de experiência na administração pública, do conhecimento da organização em que vai atuar. É preciso que o titular da instituição tenha elevado espírito público, senso de justiça e de equidade, sensibilidade social, habilidade nas relações públicas, equilíbrio, personalidade, ilibada reputação, reconhecida solvência moral e probidade a toda prova.

As análises da pesquisa demonstraram a necessidade de conhecer quais são as ações aproximativas efetuadas pelas ouvidorias, sua qualidade e efetividade, a fim de se ter condições de proceder à avaliação mais fiel. Este artigo focou um público específico, mas cabem ainda outros estudos sobre as relações com outros públicos, uma análise da relação da ouvidoria com a imprensa, com os clientes, com a gestão etc. Com certeza, eles subsidiariam ainda mais as nossas reflexões.

Para entender a complexidade do ato comunicativo, um dos caminhos é estudar alguns elementos ou aspectos relevantes presentes na gestão do processo comunicativo nas organizações: as barreiras, os níveis de análise, as

8 "Atualmente ombudsman e ouvidor são dois nomes para a mesma pessoa: alguém que, estando inserido numa organização, atua como representante dos usuários de bens e serviços fornecidos por essa organização. Um paladino dos interesses dos clientes dentro da organização - seja ela privada ou pública. Em geral, prefere-se o termo ombudsman no meio empresarial e ouvidor no serviço público, mas é aceitável 0 uso indistinto de ambos em qualquer situação" (CENTURIÃO, 2003, p. 61). 
redes, os fluxos, os meios e as diversas modalidades comunicacionais existentes (KUNSCH, 2003, p. 73).

Porém, a prática é muito mais complexa e, portanto, é preciso estabelecer uma parceria com as lideranças e para isso a ouvidoria precisa se dispor a conhecer as áreas da organização, seus processos, suas limitações. Identificar o perfil desses gestores, suas dificuldades de relacionamento interpessoal e de comunicação oral e escrita podem sinalizar empecilhos ao bom relacionamento com a ouvidoria. Sendo assim, fica evidente a necessidade de aproximação, que pode começar fazendo esse líder conhecer a ouvidoria, seu funcionamento, sua equipe e seus resultados. É preciso estabelecer um vínculo profissional e partilhar com os líderes avanços e resultados. Dessa forma, é possível consolidar a imagem de uma instituição parceira que tem o objetivo de construir e não desmontar sua área. A ouvidoria também é canal entre esses líderes e a gestão estratégica da organização quando as manifestações exigem mediação. Nesse momento ela pode colaborar com o líder para demonstrar a necessidade de determinada intervenção em prol do cliente. Para todas essas questões a aplicação de estratégias de comunicação dirigida fomenta o desenvolvimento de ações aproximativas que estreitam os laços, cria vínculos duradouros e fideliza o público.

Finalmente, vale ressaltar que estudo semelhante, se aplicado em outros estados brasileiros, pode trazer olhares distintos sobre esta abordagem e revelar tanto o desempenho dos profissionais de comunicação à frente das ouvidorias como a sua participação nesse mercado crescente que é a ouvidoria.

Os principais dados levantados com a pesquisa bibliográfica demonstraram que a ouvidoria constitui um espaço de trabalho para pesquisadores e profissionais das áreas de comunicação. Na prática, cada organização tem objetivos, cultura e valores distintos. Nesse sentido, cabe à instituição de ouvidoria conhecer, estabelecer e manter vínculos com seus públicos com coerência. Para que os resultados sejam efetivos, a ação planejada de comunicação pode contribuir sobremaneira.

\section{REFERÊNCIAS}

ANDRADE, C. Teobaldo de Souza. Para entender relações públicas. 4. ed. São Pçaulo: Loyola, 1993.

BASTOS, Marco Aurélio. A ouvidoria pública no Paraná. Monografia (Especialização em Administração Pública) - Unibrasil, Curitiba, 2006.

BONFADINI, Gerson José. 0 relacionamento das organizações com públicos: uma abordagem comparativa entre as relações públicas e o marketing de relacionamento. UNIrevista, São Leopoldo (RS), Unisinos, v. 1, n. 3, jul. 2006. Disponível em: < http:// www.unirevista.unisinos.br/_pdf/UNIrev_Bonfadini.PDF>.

.ERNEST, Robert. Corporate cultures and effective planning: an introduction to the organizational culture grid. Personnel Administrator, n. 30, March 1985 .

CENTURIÃO, Alberto. Ombudsman, a face da empresa cidadã. Rio de Janeiro: Educator, 2003.

CASTRO, Gleise. Time motivado levanta a torcida. Comunicação Corporativa, São Paulo, Valor Econômico, p. 48-50, 2008. 
GRUNIG, James E.; HON, Linda C. Measuring relationships in public relations, Gainesville, FL: Institute for Public Relations, 1999. INC - Instituto Nacional de Capacitação. [Informação fornecida por e.mail], Brasília, 2009.

KUNSCH, Margarida M. Krohling. Planejamento de relações públicas na comunicação integrada. 4. ed. - rev., atual. e ampl. São Paulo: Summus, 2003.

LIMA, Chussely Souza. Ouvidoria pública no Estado de Pernambuco: passos na perspectiva da cidadania. 2008. 160 fl. .Dissertação (Mestrado em Gestão Pública) - Universidade Federal de Pernambuco, Recife, 2008.

LOPES, Valéria de Siqueira C. Lopes. Cultura e comunicação na relação entre empresas e consumidores. In: FREITAS, Ricardo Ferreira; SANTOS, Luciane L. dos (Org.). Desafios contemporâneos da comunicação: perspectivas de relações públicas. São Paulo: Summus, 2002. p. 89-107.

MARCONDES FILHO, Ciro (Org.). Dicionário da comunicação. São Paulo: Paulus. 2009.

. Para entender a comunicação: contatos antecipados com a nova teoria. São Paulo: Paulus. 2008.

VASCONCELOS, A. Telles; OLIVEIRA, C. Feliciano. Desenvolvimento e comunicação. Seminário para a disicplina de Estudos Especiais de Comunicação. São Paulo: ECA-USP, 19979. [Mimeo].

VERGARA, Sylvia Constant. Métodos de pesquisa em administração. 2. ed. São Paulo: Atlas, 2006.

Recebido em: 17.12.2009 / Aceito em: 26.02.2010 